\title{
Mutagenic, Antimutagenic and Antioxidant Activities of a New Class of $\beta$-Glucoside Hydroxyhydroquinone from Anagallis monelli Growing in Tunisia
}

\author{
Samia Ammar, ${ }^{a}$ Mohamed Ali Mahjoub, ${ }^{a}$ Nesrine Charfi, ${ }^{a}$ Ines Skandarani,,${ }^{b}$ \\ Leila CHEKIR-GHedirA, ${ }^{b}$ and Zine Mighri* ${ }^{*}, a$ \\ ${ }^{a}$ Laboratoire de Chimie des Substances Naturelles et de Synthèse Organique 99/UR/12-26, Faculté des Sciences de \\ Monastir; 5000 Monastir, Tunisie: and ${ }^{b}$ Unité de Pharmacognosie/Biologie moléculaire 99/UR/07-03, Faculté de \\ Pharmacie de Monastir; Rue Avicenne 5000 Monastir, Tunisie. Received August 29, 2006; accepted November 28, 2006
}

\begin{abstract}
A new skeleton of an $O$-heteroside natural substance named zinolol, the first representative of a new class of aminated hydroxyhydroquinone, has been isolated from the whole plant Anagallis monelli. Its structure has been established by one and two dimensional NMR spectroscopic procedures. Antioxidant, mutagenic, antimutagenic activities were realised and positive results were recorded.
\end{abstract}

Key words Anagallis monelli; new O-heteroside; mutagenic; antimutagenic; antioxidant

As a part of our investigation into some medicinal plants growing in Tunisia ${ }^{1-4)}$ and in order to continue our search on potential biological natural compounds, we report below the isolation, the structure elucidation and biological activities of a new O-heteroside zinolol, identified in the methanolic extract of the whole Anagallis monelli ssp. linifolia (L.) (Primulaceae). The Tunisian flora counts six species of anagallis, the most preponderant one is arvensis. ${ }^{5)}$ According to our bibliographic studies and contrary to the arvensis species, no much is known on the chemistry of Anagallis monelli. We note that in folk medicine the decoction of the genre Anagallis has fungistatic proprieties. ${ }^{6}$ Occurrence of saponins in $a r$ vensis species ${ }^{7,8)}$ explains its traditional uses as antifungic. Saponins from Anagallis arvensis were also mentioned as antiviral agent against herpes simplex virus and poliovirus. ${ }^{9)}$ With an aim to focus in the biological interest of the species monelli, mutagenic and antimutagenic activities were realised based on the SOS Chromotest and antioxidant activities were realised based on the 2,2'-azinobis-(3-ethylbenzothiazoline-6-sulfonic acid) diammonium salt (ABTS) and 1,1-diphenyl-2-picrylhydrazyl (DPPH) tests. The structure of zinolol was established by the spectroscopic means ( 1 and 2D NMR experiments). The presence of $N$-methylaminomethylene group on the aromatic ring of the $2-(O-\beta$-Dglucosyl)hydroxyhydroquinone enables us to confirm the originality of this natural substance, named systematically, 2( $O$ - $\beta$-D-glucosyl)-6-(methylaminomethyl)hydroxyhydroquinone. The mutagenic potential of zinolol in the SOS chromotest shows significant activities; in the same way antioxidant capacity of this substance was noteworthy.

\section{Results and Discussion}

Structure Elucidation Zinolol was isolated as amorphous solid. Negative ion electrospray ionization mass spectrum of this substance shows the pseudomolecular pick $[\mathrm{M}-\mathrm{H}]^{-}$at $\mathrm{m} / \mathrm{z} 330$ and confirms the molecular formula $\mathrm{C}_{14} \mathrm{H}_{21} \mathrm{NO}_{8}$. The ${ }^{13} \mathrm{C}$-NMR spectrum exhibits the presence of 14 carbon atoms whose multiplicity assignments were made by DEPT 135 experiment. Observation of five peaks at 62.5 , $71.2,75.7,78.3$ and $78.7 \mathrm{ppm}$ relative respectively to carbons $\mathrm{C}_{6^{\prime}}, \mathrm{C}_{4^{\prime}}, \mathrm{C}_{2^{\prime}}, \mathrm{C}_{3^{\prime}}$ and $\mathrm{C}_{5^{\prime}}$ prove the presence of a glucosyl ring. $\mathrm{H}_{6^{\prime}}-\mathrm{C}_{6^{\prime}} ; \mathrm{H}_{4^{\prime}}-\mathrm{C}_{4^{\prime}} ; \mathrm{H}_{2^{\prime}}-\mathrm{C}_{2^{\prime}} ; \mathrm{H}_{3^{\prime}}-\mathrm{C}_{3^{\prime}}$ and $\mathrm{H}_{5^{\prime}}-\mathrm{C}_{5^{\prime}}$ correla- tions observed on the CHCorr spectrum confirm also the presence of the five glucosyl protons $\mathrm{H}_{6^{\prime}}, \mathrm{H}_{4^{\prime}}, \mathrm{H}_{2^{\prime}}, \mathrm{H}_{3^{\prime}}$ and $\mathrm{H}_{5^{\prime}}$, the anomeric proton $\mathrm{H}_{1^{\prime}}$ was also observed at $4.49 \mathrm{ppm}$. The anomeric coupling constant value of $7.2 \mathrm{~Hz}$ confirms the $\beta$ configuration of the glucosyl moiety. ${ }^{10)}$

The $\mathrm{H}-\mathrm{H}$ COSY correlations $\mathrm{H}_{1^{\prime}}-\mathrm{H}_{2^{\prime}} ; \mathrm{H}_{2^{\prime}}-\mathrm{H}_{3^{\prime}} ; \mathrm{H}_{4^{\prime}}-\mathrm{H}_{5^{\prime}}$ and $\mathrm{H}_{5^{\prime}}-\mathrm{H}_{6^{\prime}}$ and those of the HMBC spectrum represented in Table 1 permit us to establish the total skeleton of the $O-\beta$-Dglucosyl moiety. Based on the HMBC spectrum the aromatic aglycone structure was established. Apparition of the methylene group $\left(\mathrm{H}_{1^{\prime \prime} \mathrm{a}}\right.$ and $\mathrm{H}_{1^{\prime \prime} \mathrm{b}} \delta$ respectively 3.87 and $\left.4.02 \mathrm{ppm}\right)$ as doublet (d) for each proton at the position 1" was probably due to the hydrogen bond. Position of the methyl-

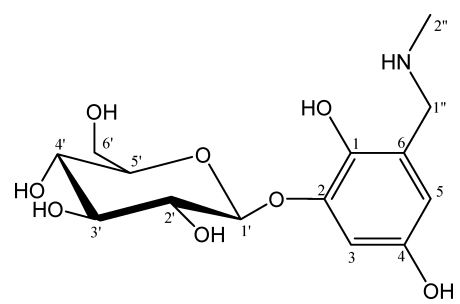

Fig. 1. Structure of Zinolol

Table 1. ${ }^{1} \mathrm{H}$ - and ${ }^{13} \mathrm{C}-\mathrm{NMR}$ Chemical Shifts of Zinolol in $\mathrm{CD}_{3} \mathrm{OD}$ and ${ }^{13} \mathrm{C}$ ${ }^{1} \mathrm{H}$ Correlations (HMBC)

\begin{tabular}{lccc}
\hline \hline Atom & $\delta^{13} \mathrm{C}(\mathrm{ppm})$ & $\delta^{1} \mathrm{H}(\mathrm{ppm}) ; J(\mathrm{~Hz})$ & $\mathrm{HMBC}$ \\
\hline 1 & 139.1 & - & $\mathrm{H}_{1^{\prime \prime} \mathrm{a}}-\mathrm{C}_{1}, \mathrm{H}_{1^{\prime \prime} \mathrm{b}}-\mathrm{C}_{1}$ \\
2 & 152.0 & - & $\mathrm{H}_{3}-\mathrm{C}_{2}$ \\
3 & 104.1 & $6.12(1 \mathrm{H}, \mathrm{d}) ; J_{3-5}=3.00$ & $\mathrm{H}_{5}-\mathrm{C}_{3}$ \\
4 & 156.3 & - & $\mathrm{H}_{3}-\mathrm{C}_{4}$ \\
5 & 109.8 & $6.32(1 \mathrm{H}, \mathrm{d}) ; J_{5-3}=3.00$ & $\mathrm{H}_{3}-\mathrm{C}_{5}, \mathrm{H}_{1^{\prime \prime}}-\mathrm{C}_{5}, \mathrm{H}_{1^{\prime \prime}}-\mathrm{C}_{5}$ \\
6 & 131.3 & - & $\mathrm{H}_{1^{\prime \prime}}-\mathrm{C}_{6}, \mathrm{H}_{1^{\prime \prime}}-\mathrm{C}_{6}$ \\
$1^{\prime}$ & 108.1 & $4.49(1 \mathrm{H}, \mathrm{d}) ; J_{1^{\prime}-2^{\prime}}=7.2$ & $\mathrm{H}_{2^{\prime}}-\mathrm{C}_{1^{\prime}}$ \\
$2^{\prime}$ & 75.7 & $3.48(1 \mathrm{H}, \mathrm{m})$ & $\mathrm{H}_{1^{\prime}}-\mathrm{C}_{2^{\prime}}, \mathrm{H}_{3^{\prime}}-\mathrm{C}_{2^{\prime}}$ \\
$3^{\prime}$ & 78.3 & $3.46(1 \mathrm{H}, \mathrm{m})$ & $\mathrm{H}_{2^{\prime}}-\mathrm{C}_{3^{\prime}}, \mathrm{H}_{4^{\prime}}-\mathrm{C}_{1^{\prime}}$ \\
$4^{\prime}$ & 71.2 & $3.49(1 \mathrm{H}, \mathrm{m})$ & $\mathrm{H}_{5^{\prime}}-\mathrm{C}_{4^{\prime}}, \mathrm{H}_{3^{\prime}}-\mathrm{C}_{4^{\prime}}$ \\
$5^{\prime}$ & 78.7 & $3.30(1 \mathrm{H}, \mathrm{m})$ & $\mathrm{H}_{4^{\prime}}-\mathrm{C}_{5^{\prime}}, \mathrm{H}_{3^{\prime}}-\mathrm{C}_{5^{\prime}}$ \\
$6^{\prime}$ & 62.5 & $3.84(2 \mathrm{H}, \mathrm{m})$ & $\mathrm{H}_{5^{\prime}}-\mathrm{C}_{6^{\prime}}$ \\
$1^{\prime \prime} \mathrm{a}$ & 46.7 & $4.04(1 \mathrm{H}, \mathrm{d}) ; J_{1 \mathrm{a}^{\prime \prime}-1 \mathrm{~b}^{\prime \prime}}=16.2$ & $\mathrm{H}_{5}-\mathrm{C}_{1^{\prime \prime}}$ \\
$1^{\prime \prime} \mathrm{b}$ & 46.7 & $4.02(1 \mathrm{H}, \mathrm{d}) ; J_{1 b^{\prime \prime}-1 \mathrm{a}^{\prime \prime}}=16.2$ & - \\
$2^{\prime \prime}$ & 30.1 & $2.23(3 \mathrm{H}, \mathrm{s})$ & - \\
\hline
\end{tabular}


Table 2. Mutagenicity and Antimutagenicity Results of Zinolol to Escherichia coli PQ37 against the Mutagen Nifuroxazide

\begin{tabular}{|c|c|c|c|c|c|c|}
\hline & Concentration $(\mathrm{mg} / \mathrm{ml})$ & $\mathrm{U}_{\beta}$ & $\mathrm{U}_{\mathrm{P}}$ & $\mathrm{R}$ & IF & Results \\
\hline \multirow[t]{2}{*}{ Nifuroxazide } & 0 & 2.5 & 7.86 & 0.31 & - & - \\
\hline & + & 34.75 & 5.05 & 6.88 & 22.19 & - \\
\hline \multirow{4}{*}{ Mutagenic activity } & 50 & 1.81 & 4.9 & 0.36 & 1.16 & Non mutagen \\
\hline & 10 & 2.19 & 5.27 & 0.41 & 1.32 & Non mutagen \\
\hline & 2 & 1.61 & 4.4 & 0.36 & 1.18 & Non mutagen \\
\hline & & & & & & Genotoxcicity inhibition (\%) \\
\hline \multirow[t]{3}{*}{ Antimutagenic activity } & 50 & 13.17 & 4.15 & 3.17 & 10.23 & 56.44 \\
\hline & 10 & 10.76 & 3.9 & 2.75 & 8.89 & 62.76 \\
\hline & 2 & 6.24 & 3.65 & 1.70 & 5.48 & 78.85 \\
\hline
\end{tabular}

Table 3. $\mathrm{ABTS}^{+\cdot}$ and $\mathrm{DPPH}^{*}$ Inhibition Percentage in the Presence of Different Concentrations of Zinolol

\begin{tabular}{|c|c|c|c|c|c|}
\hline \multirow{3}{*}{ Concentration $(\mathrm{mg} / \mathrm{ml})$} & \multicolumn{4}{|c|}{ ABTS \% inhibition } & \multirow[t]{2}{*}{ DPPH } \\
\hline & \multicolumn{4}{|c|}{ Time (min) } & \\
\hline & 5 & 10 & 15 & 20 & 30 \\
\hline 1 & $97.0 \pm 0.1$ & $97.0 \pm 0.3$ & $97.1 \pm 0.3$ & $97.8 \pm 0.3$ & $97.8 \pm 0.1$ \\
\hline 0.5 & $97.7 \pm 0.7$ & $97.7 \pm 0.6$ & $97.8 \pm 0.6$ & $97.7 \pm 0.7$ & $86.1 \pm 1.6$ \\
\hline 0.25 & $82.5 \pm 4.7$ & $89.1 \pm 3.1$ & $94.6 \pm 2.3$ & $97.6 \pm 1.6$ & $76.8 \pm 1.1$ \\
\hline 0.125 & $69.8 \pm 7.8$ & $79.7 \pm 6.8$ & $87.1 \pm 5.7$ & $91.8 \pm 4.6$ & $71.4 \pm 0.8$ \\
\hline 0.06 & $78.2 \pm 9.5$ & $84.3 \pm 9.1$ & $88.8 \pm 8.3$ & $89.1 \pm 4.4$ & $69.3 \pm 1.6$ \\
\hline 0.03 & $70.1 \pm 5.4$ & $79.8 \pm 7.4$ & $83.2 \pm 6.5$ & $87.2 \pm 6.2$ & $25.8 \pm 0.5$ \\
\hline
\end{tabular}

aminomethyl fragment attached to the carbon $\mathrm{C}_{6}$ was determined via the $\mathrm{HMBC}$ correlations $\mathrm{H}_{1^{\prime \prime} \mathrm{a}}-\mathrm{C}_{6} ; \mathrm{H}_{1^{\prime \prime} \mathrm{b}}-\mathrm{C}_{6} ; \mathrm{H}_{1^{\prime \prime} \mathrm{a}}-\mathrm{C}_{1}$; $\mathrm{H}_{1^{\prime \prime} \mathrm{b}}-\mathrm{C}_{1} ; \mathrm{H}_{1^{\prime \prime} \mathrm{a}}-\mathrm{C}_{5}$ and $\mathrm{H}_{1^{\prime \prime} \mathrm{b}}-\mathrm{C}_{5}$. From the HMBC spectrum the long-range heteronuclear correlations $\mathrm{H}_{2^{\prime \prime}}-\mathrm{C}_{1^{\prime \prime}}$ and $\mathrm{H}_{1^{\prime \prime} \mathrm{a}, \mathrm{b}}-\mathrm{C}_{2^{\prime \prime}}$ were observed. The $\mathrm{NH}$ nitrogen group position was also confirmed based on the COSY 2D relay experiment. On the ${ }^{1} \mathrm{H}$ spectrum the methyl group appears as a singulet this multiplicity was explained by the exchange of the amine proton. The COSY relay experiment shows methyl group correlations $\mathrm{H}_{1^{\prime \prime} \mathrm{a}}-\mathrm{H}_{2^{\prime \prime}} ; \mathrm{H}_{1^{\prime \prime} \mathrm{b}}-\mathrm{H}_{2^{\prime \prime}}$, that allows us to identify the full coupled spin network $\left\{-\mathrm{CH}_{2^{\prime \prime}}-\mathrm{NH}-\mathrm{CH}_{1^{\prime \prime}}\right\}$.

The study of the Noe effects in zinolol permit us to confirm the $\beta$ configuration of the glucosyl moiety via the correlations $\mathrm{H}_{1},-\mathrm{H}_{5^{\prime}}$ and $\mathrm{H}_{1^{\prime}}-\mathrm{H}_{3^{\prime}}$. Our deep bibliographic study on hydroquinones shows the skeleton originality of the present natural substance, and confirms that it is the first representative of a new class of hydroxyhydroquinone. The water solubility of zinolol encouraged us to focus on its biological activity and especially on its prevention of mutagenicity and radical toxicity. Indeed hydroxyhydroquinone derivatives were endowed by many activities; they show inhibition of HIV-1 proteinase ${ }^{11)}$ and activities of hydratase ${ }^{12)}$ and amine oxidase. ${ }^{13)}$

E. coli Mutagenicity Assay The genotoxicity of zinolol was studied using the SOS chromotest (Table 2). At different concentrations and even with high concentration $(50 \mathrm{mg} / \mathrm{ml})$ our substance seems cause no mutagenic effects. Compared with the positive control ( $\mathrm{IF}=22.19$ at a concentration of $1 \mathrm{mg} / \mathrm{ml}$ ) zinolol induction factor was constantly feeble (IF $\approx 1)$. According to Mesch-Sundermann, a compound with an IF lower then 2.00 was classified as non genotoxic. ${ }^{14}$ Therefore we can prove that zinolol is a non genotoxic com- pound.

Antimutagenic Activity This test was based on the inhibition of the SOS inducing factor (IF), after co-incubation of the positive mutagenic compound nifuroxazide and the tested substance zinolol. Results were expressed as percentage of genotoxicity inhibition relative to positive nifuroxazide (Table 2). Application of zinolol with exponential value concentrations shows genotoxicity inhibition rising from 56.44 to $78.85 \%$. As shown in Table 2 unexpected results were recorded, zinolol was more active with feeble concentrations it shows maximum genotoxicity inhibition of $78.85 \%$ at a concentration of $2 \mathrm{mg} / \mathrm{ml}$. Complementary experiments are necessary to explain the concentration related inhibitory effects of zinolol, perhaps in the presence of another positive chemical mutagen.

Radical Cation ABTS $^{+\cdot}$ Scavenging Activity Results of our investigation on $\mathrm{ABTS}^{+}$cation radicals scavenging activity, represented by Table 3 , show maximal inhibition percentage of $97.8 \%$ at a zinolol concentration of $1 \mathrm{mg} / \mathrm{ml}$. At feeble concentration $(0.03 \mathrm{mg} / \mathrm{ml})$ and immediately after $5 \mathrm{~min}$ of incubation zinolol displays a value of $70 \%$ of ABTS $^{+\cdot}$ inhibition. Compared to Trolox $(97.9 \%$ inhibition at $1 \mathrm{mg} / \mathrm{ml}$ and after $5 \mathrm{~min}$ of incubation), zinolol, is gifted of a very powerful antioxidant activity against $\mathrm{ABTS}^{+}$cation radicals.

DPPH ${ }^{*}$ Scavenging Capacity The result of antioxidant activity of zinolol, against free radical $\mathrm{DPPH}^{\circ}$ and after 30 min of incubation, was represented by Table 3 . Compared to Trolox as a standard reference product $(99.3 \%$ inhibition at $1 \mathrm{mg} / \mathrm{ml}$ and after $30 \mathrm{~min}$ of incubation), we note that our natural substance shows also powerful inhibition activity. The increase of the inhibition percentage from 25.8 to 
97.1\%, shows the dose-dependence of the zinolol antioxidant effect.

The in vitro test of zinolol against toxic radical entities $\mathrm{ABTS}^{+}{ }^{-}$and $\mathrm{DPPH}{ }^{-}$proves the efficiency of this substance as an antioxidant agent. Indeed the remarkable activity of zinolol is awaited. Based on the structure-activity relationship of polyphenols compounds, ${ }^{15)}$ oxidation of hydroquinone skeleton results with the formation of the quinone stable form.

Along this study we are focusing on the interest of a new natural substance, isolated from the plant Anagallis monelli, as a strong agent against the genotoxicity and the oxidative effects caused by free radicals. The safety of zinolol and the genotoxicity-anticancer activity relationship ${ }^{16)}$ were two reasonable reasons to continue our research and to focus on the anticancer effects of our natural compounds.

\section{Experimental}

General Experimental Procedures ${ }^{1} \mathrm{H}-,{ }^{13} \mathrm{C}-\mathrm{NMR}$ and two-dimensional NMR spectra were obtained with Bruker WP 300 spectrometer at $300 \mathrm{MHz}$ for ${ }^{1} \mathrm{H}-\mathrm{NMR}$ and $75 \mathrm{MHz}$ for ${ }^{13} \mathrm{C}$-NMR. Measurements were made in $\mathrm{CD}_{3} \mathrm{OD}$ at $27^{\circ} \mathrm{C}$, and the resonance of residual solvent were used as internal references. Hxcoqf and inv4lplrndqf heteronucleair pulse programs were used respectivelly for CHCorr and HMBC experiments; 2D homonuclear correlation pulse programs, Cosyqf45 and Cosyqfrl were used for COSY experiments. NOESY experiment was performed based on the noesyph pulse program. ES-MS spectrum was recorded in negative switching mode, using a HP 1100 MSD apparatus. FT-IR spectrum was measured on a PerkinElmer $157 \mathrm{G}$ infrared spectro-photometer. Polax-2L instrument was used to determine the optical rotation. Optical density values were mesured on Hitachi Fluorescence (model 4010) and Shimadzu UV-2101 PC Spectrophotometers respectively for genotoxicity and antioxidant activities.

Plant Material Aerial parts (leaves, stems and fruit) of the plant Anagallis monelli $(1200 \mathrm{~g})$ were collected at the beginning of May 2002 in Sousse (centre of Tunisia). A voucher specimen was deposited at the herbarium in the Faculty of Sciences, University of Monastir, Tunisia.

Extraction and Isolation Dried and finely powdered Anagallis monelli aerial part $(1200 \mathrm{~g})$ was immersed in $\mathrm{MeOH}(4 \times 21)$ at room temperature for a week. Methanolic extract was filtered then evaporated to dryness. The $\mathrm{MeOH}$ extract $(360 \mathrm{~g})$ was extracted with AcOEt (11). Removal of the solvent from the AcOEt solution gave a methanolic residue symbolized E1 $(147 \mathrm{~g})$ and an oily substance $(212 \mathrm{~g})$. Extraction of the oily substance with petroleum ether yield an ethyl acetate residue symbolized E2 $(127 \mathrm{~g})$ and a petroleum ether extract $(86 \mathrm{~g})$. The ethyl acetate residue E2 was fractioned by silica gel column chromatography (CC) eluted with a step-gradient of AcOEt in petroleum ether. Fifteen fractions (F1 to F15) were collected. Repeated CC separations of the twelfth fraction $(2764 \mathrm{mg})$ afforded in pure form the natural compound zinolol (126 mg).

Chemicals The mutagen Nifuroxazide, the $o$-nitrophenyl- $\beta$-D-galactopyranoside and $n$-nitrophenyl-phosphate, for colorimetric evaluation of $\beta$ galactosidase and alkaline phosphatase, were purchased from Sigma. (ABTS), (DPPH) and 6-hydroxy-2,5,7,8-tetramethylchroman-2-carboxylic acid (Trolox) were also obtained from Sigma. All other chemicals were of analytical grade purity

E. coli Mutagenicity Assay Genotoxicity assay of zinolol was carried out using SOS chromotest. This test is based on using the genetically modified Escherichia coli PQ37 strain, in which the lacZ is under the control of the sfiA geneb. ${ }^{17)}$ In short, genotoxicity in samples was detected measuring the activation of SOS response of tester organism by evaluating $\beta$-galactosidase induction and alkaline phosphatase expression. The $\beta$-galactosidase and alkaline phosphatase activities were calculated according to Quillardet and Hofnung, ${ }^{18)}$ Units $=\mathrm{U}_{(\beta, \mathrm{p})}=\mathrm{A}_{420} \times 10^{3} / \mathrm{t}\left(\mathrm{A}_{420}=\right.$ optical density at $420 \mathrm{~nm}$ for the tested molecule at a determined concentration; $t$ : substrate conversion time in $\mathrm{min}$ ). The induction factor (IF) was calculated as the ratio $\mathrm{R} / \mathrm{R}_{\mathrm{o}}$ with $\mathrm{R}=\mathrm{U}_{\beta} / \mathrm{U}_{\mathrm{P}}\left(\mathrm{U}_{\beta}=\beta\right.$-galactosidase activity and $\mathrm{U}_{\mathrm{P}}=$ alkaline phosphatase activity at zinolol determined concentration; $\mathrm{R}_{\mathrm{o}}=\beta$-galactosidase activity/alkaline phosphatase activity at test compound concentration zero). A positive control, Nifuroxazide was used as reference genotoxic compound.

Antimutagenic Activity The antimutagenic activity was carried out with the same method as that described for the study of the mutagenic activ- ity, except the incubation of the mutagen agent at the same time as the tested substance. ${ }^{19)}$ The same concentrations of molecules used for the study of the mutagenic activity, are used for the study of the antimutagenic activity. All experiments were performed in triplicate.

Radical Cation ABTS ${ }^{+}$Scavenging Activity The standard method described by Miller $e t a l .^{20)}$ has been adopted with minor modifications. This assay assesses the total radical scavenging capacity based on the ability of a compound to scavenge the stable ABTS radical $\left(\mathrm{ABTS}^{+}\right)$. The blue green ABTS radical form was produced through the reaction between ABTS and potassium persulfate in water. A concentrated $\mathrm{ABTS}^{+\cdot}$ stock solution was diluted with phosphate buffered saline (PBS), $\mathrm{pH} 7.4$ to a final absorbance of $0.70 \pm 0.02$ with a wavelength of $734 \mathrm{~nm}$ and at a temperature of $37^{\circ} \mathrm{C}$. Solutions with different diluted concentrations of zinolol, were prepared in ethanol. Ten microliters of an antioxidant containing studied solution were added to $990 \mathrm{ml} \mathrm{ABTS}{ }^{+\cdot}$ solution and the absorbance at $734 \mathrm{~nm}$ was measured. Sample absorbance was compared to a blank where $10 \mu \mathrm{l}$ of the solvent were added to $990 \mathrm{ml}$ of the $\mathrm{ABTS}^{+\cdot}$ solution. Absorbance was measured at 5, 10, 15 and $20 \mathrm{~min}$ after addition of the antioxidant. Results were expressed in inhibition percentage versus samples concentrations $(\mathrm{mmol})$ at different times.

DPPH' Scavenging Capacity The DPPH radical scavenging capacity of zinolol was measured from the bleaching of purple colored ethanol solution of DPPH. Method described by Hatano et al..$^{21)}$ has been used. $0.5 \mathrm{ml}$ of each sample concentration was mixed with a same volume of DPPH ethanolic solution. After incubation of $30 \mathrm{~min}$ in darkness at room temperature, absorbance was read at $520 \mathrm{~nm}$ wavelength. A mixture of $0.5 \mathrm{ml}$ of DPPH solution and $0.5 \mathrm{ml}$ of ethanol was taken as a blank. Decrease in absorption induced by the tested compounds was compared to that of the positive control Trolox. $\mathrm{IC}_{50}$ values calculated denote the concentration (microgram of natural substance per milliliter of ethanol) required to scavenge $50 \%$ of DPPH radicals. All measurements were performed in triplicate. Results were expressed in inhibition percentage versus samples concentrations $(\mathrm{mg} / \mathrm{ml})$ at $30 \mathrm{~min}$.

Zinolol: Amorphous solid, mp $164-166^{\circ} \mathrm{C} .[\alpha]_{\mathrm{D}}^{25}-375^{\circ}(c=0.04$, methanol). IR (KBr) $\gamma_{\max }: 3348,2923,1699,1603,1471 \mathrm{~cm}^{-1}$. UV $\lambda_{\max }$ $(\mathrm{MeOH}) \mathrm{nm}(\varepsilon): 244(10450) .{ }^{1} \mathrm{H}-$ and ${ }^{13} \mathrm{C}-\mathrm{NMR}$ data, see Table 1. ES-MS $[\mathrm{M}-\mathrm{H}]^{-}$at $m / z 330\left(\mathrm{C}_{14} \mathrm{H}_{21} \mathrm{NO}_{8}, 331\right)$.

Acknowledgments The authors wish to thank Dr. F. Harzallah-Skhiri, laboratoire de Biologie végétale, Ecole Supérieure d'horticulture et d'Elevage, Chott Mériem, Sousse, Tunisia, for botanical classification of the plant material.

\section{References}

1) Mahjoub M. A., Ammar S., Mighri Z., Nat. Prod. Res., 19, 723-729 (2005).

2) Braham H., Mighri Z., Ben Jannet H., Matthew S., Abreu P., J. Nat. Prod., 68, 517-522 (2005).

3) Ammar S., Mahjoub M. A., Mighri Z., J. Soc. Chim. de Tunisie, 6, 9 16 (2004).

4) Mahjoub M. A., Ammar S., Mighri Z., J. Soc. Alger. Chim., 14, 293297 (2004).

5) Pottier Alapetite G., "Flore de la Tunisie," Publications Scientifiques Tunisienne, Tunis, 1981.

6) E. le Floc'h., "contribution à une étude ethnobotanique de la Flore Tunisienne," Tunisian scientific publication, officially printing of Tunisian Republic, Tunis, 1983

7) Amoros M., Girre R. L., Phytochemistry, 26, 787-791 (1987).

8) Mahato S. B., Sahu N. P., Roy S. K., Sen S., Tetrahedron, 47, 52155230 (1991).

9) Amoros M., Fauconnierb a. B., Girrea R. L., Antiviral Res., 8, 13-25 (1987).

10) Khaled M. M., Hashim A. H., Kazuhiro O., Ryoji K., Kazuo Y., Phytochemistry, 53, 401-404 (2000).

11) Ross I. B., David P. F., Biochim. Biophys. Acta Protein-Structure Mol. Enzymol., 1253, 5-8 (1995).

12) Bohuslavek J., Chanama S., Crawford R. L., Xun L., Biodegradation, 16, 353-362 (2005).

13) Alberti G., Rinaldi A., Finazziagro A., Biochem. Biophys. Res. Commun., 208, 825-834 (1995).

14) Mesch-Sundermann V., Mochayedi S., Kevekordes S., Mutation Res., 278, 1—9 (1992).

15) Pietta P. G., J. Nat . Prod., 63, 1035-1042 (2000).

16) Lynnette R., Philpott F. M., Karunasinghe N., Toxicology, 198, 147- 
159 (2004)

17) Quillardet P., Hofnung M., Mutation Res., 297, 235-279 (1993).

18) Quillardet P., de Bellecombe C., Hofnung M., Mutation Res., 147, 79-95 (1985)

19) Raipulis J., Toma M. M., Semjonovs P., Int. J. Food Microbiol., 102,
$343-347$ (2005).

20) Miller N. J., Rice-Evans C. A., Davies M. J., Gopinathan V., Milner A., Clin. Sci., 84, 407-412 (1993).

21) Hatano T., Kagawa H., Yasuhara T., Okuda T., Chem. Pharm. Bull., 36, 2090-2097 (1988). 